\title{
Gabapentin reduces preoperative anxiety and pain catastrophizing in highly anxious patients prior to major surgery: a blinded randomized placebo-controlled trial \\ La gabapentine réduit l'anxiété préopératoire et la catastrophisation de la douleur chez les patients très anxieux avant une chirurgie majeure: une étude randomisée contrôlée par placebo et en aveugle
}

\author{
Hance Clarke, MD • Kyle R. Kirkham, MD • Beverley A. Orser, MD, PhD • \\ Rita Katznelson, MD • Nicholas Mitsakakis, PhD • Raynauld Ko, MD • \\ Adam Snyman, MD • Martin Ma, MD • Joel Katz, PhD
}

Received: 25 September 2012/Accepted: 14 January 2013/Published online: 2 February 2013

(C) Canadian Anesthesiologists' Society 2013

\begin{abstract}
Introduction Gabapentin is increasingly being used for the treatment of postoperative pain and a variety of psychiatric diseases, including chronic anxiety disorders. Trials have reported mixed results when gabapentin has been administered for the treatment of preoperative anxiety. We tested the hypothesis that gabapentin 1,200 mg vs

Author contributions Hance Clarke is the primary author of this manuscript. He is responsible for designing the study and reviewing the analysis of the data. Joel Katz is the senior author. Kyle Kirkham is a co-author of the manuscript. Kyle Kirkham, Raynauld Ko, and Joel Katz helped design the study. Kyle Kirkham and Joel Katz helped review the analysis of the data. Kyle Kirkham, Beverley Orser, Rita Katznelson, Adam Snyman, Raynauld Ko, Martin Ma, and Joel Katz contributed to the writing of the manuscript. Beverley Orser helped to develop the initial protocol. Nicholas Mitsakakis is the biostatistician responsible for the analysis of the data.
\end{abstract}

H. Clarke, MD $(\bowtie) \cdot$ K. R. Kirkham, MD · R. Katznelson, MD N. Mitsakakis, PhD · R. Ko, MD · A. Snyman, MD ·

M. Ma, MD · J. Katz, PhD

Department of Anesthesia and Pain Management, Toronto General Hospital, 200 Elizabeth Street, Eaton North 3 EB 317, Acute Pain Research Unit, Toronto, ON M5G 2C4, Canada

e-mail: hance.clarke@utoronto.ca

H. Clarke, MD - B. A. Orser, MD, PhD

Department of Anesthesiology, Sunnybrook Health Sciences

Centre, Toronto, ON, Canada

H. Clarke, MD - K. R. Kirkham, MD - B. A. Orser, MD, PhD .

R. Katznelson, MD · R. Ko, MD · A. Snyman, MD .

M. Ma, MD · J. Katz, PhD

Department of Anesthesia, University of Toronto,

Toronto, ON, Canada placebo would reduce preoperative anxiety in patients who exhibit moderate to high preoperative anxiety.

Methods A blinded randomized controlled trial was conducted from September 2009 to June 2011 at the Toronto General Hospital. Following ethics approval and informed consent, 50 female patients with a 0-10 numeric rating scale (NRS) anxiety score of greater than or equal to $5 / 10$ consented to receive either gabapentin $1,200 \mathrm{mg}$ $(n=25)$ or placebo $(n=25)$ prior to surgery. Randomization was computer generated, and the Investigational Pharmacy was responsible for the blinding and dispensing of medication. All patients and care providers, including physicians, nurses, and study personnel, were blinded to group allocation. Before administering the study medication, baseline anxiety levels were measured using a NRS, the

N. Mitsakakis, $\mathrm{PhD}$

Toronto Health Economics and Health Technology Assessment (THETA) Collaborative, University of Toronto, 144 College

Street, Room 658, Toronto, ON M5S 3M2, Canada

J. Katz, PhD

Department of Psychology, York University,

Toronto, ON, Canada 
Spielberger State-Trait Anxiety Inventories, the Pain Catastrophizing Scale, and the Pain Anxiety Symptoms Scale-20. Baseline pain intensity (0-10 NRS) and level of sedation (0-10 NRS and Richmond Agitation-Sedation Scale [RASS]) were also measured. Two hours after the administration of gabapentin or placebo (prior to surgery), patients again rated their anxiety, pain, and sedation levels using the same measurement tools as at baseline. The main outcome was a reduction in preoperative anxiety.

Results Forty-four patients (22 treated with gabapentin 1,200 $\mathrm{mg}$ and 22 treated with placebo) were included in the analysis of the primary outcome. Analysis of covariance in which pre-drug NRS anxiety scores were used as the covariate showed that post-drug preoperative NRS anxiety (Effect size, 1.44; confidence interval [CI] 0.19 to 2.70) and pain catastrophizing (Effect size, 0.43; CI 0.12 to 0.74) scores were significantly lower in the gabapentin group than in the placebo control group, respectively. Post-drug sedation (Effect size, $-3.02 ; C I-4.28$ to -1.77 ) and RASS (Effect size, 0.41; CI 0.12 to 0.71) scores were significantly higher in the gabapentin group than in the placebo group, respectively.

Conclusions Administration of gabapentin $1,200 \mathrm{mg}$ prior to surgery reduces preoperative NRS anxiety scores and pain catastrophizing scores and increases sedation prior to entering the operating room. These results suggest that gabapentin 1,200 $\mathrm{mg}$ may be a treatment option for patients who exhibit high levels of preoperative anxiety and pain catastrophizing; however, the sedative properties of the medication and the possibility of delayed postoperative discharge in the elective ambulatory population need to be considered.

\section{Résumé}

Introduction La gabapentine est de plus en plus utilisée pour le traitement de la douleur postopératoire ainsi que pour le traitement de plusieurs maladies psychiatriques, notamment les troubles anxieux chroniques. Des études ont rapporté des résultats mitigés lors de l'administration de gabapentine pour le traitement de l'anxiété préopératoire. Nous avons testé l'hypothèse que $1200 \mathrm{mg}$ de gabapentine vs. un placebo réduirait l'anxiété préopératoire chez les patients manifestant une anxiété préopératoire modérée à élevée.

Méthode Nous avons réalisé une étude randomisée contrôlée en aveugle entre septembre 2009 et juin 2011 à l'Hôpital général de Toronto. Après avoir obtenu l'approbation du comité d'éthique et le consentement éclairé des sujets de l'étude, 50 patientes ayant un score d'anxiété sur une échelle d'évaluation numérique (ÉÉN) de 0-10 supérieur ou égal à 5/10 ont consenti à recevoir $1200 \mathrm{mg}$ de gabapentine $(n=25)$ ou un placebo $(n=25)$ avant la chirurgie. La randomisation a été effectuée par ordinateur, et le département de pharmacie était en charge de la mise en aveugle et de l'administration du médicament. Personne parmi les patientes ou les fournisseurs de soins, $y$ compris les médecins, les infirmières et le personnel de recherche, ne connaissait l'attribution des groupes. Avant l'administration du médicament à l'étude, les niveaux d'anxiété de base ont été mesurés à l'aide d'une ÉÉN, des inventaires d'anxiété situationnelle et de trait d'anxiété de Spielberger, de l'échelle de catastrophisation de la douleur, et de l'échelle des symptômes d'anxiété face à la douleur 20. L'intensité de la douleur de base (ÉÉN 0-10) et le niveau de sédation (ÉÉN 0-10 et échelle de sédation-agitation de Richmond [RASS]) ont également été mesurés. Deux heures après l'administration de la gabapentine ou du placebo (avant la chirurgie), les patientes ont à nouveau attribué une note à leur anxiété, à leur douleur, et aux niveaux de sédation à l'aide des mêmes outils de mesure qu'au debut. Le critère d'évaluation principal était une réduction de l'anxiété préopératoire.

Résultats Quarante-quatre patientes (22 traitées avec $1200 \mathrm{mg}$ de gabapentine et 22 traitées avec placebo) ont été incluses dans l'analyse du critère d'évaluation principal. L'analyse de la covariance, utilisant les scores d'anxiété sur l'ÉÉN avant l'administration du médicament comme covariable, a démontré que les scores d'anxiété préopératoire sur l'ÉÉN après l'administration du médicament (ampleur de l'effet, 1,44; intervalle de confiance [IC] 0,19 à 2,70) et de catastrophisation de la douleur (ampleur de l'effet, 0,43; IC 0,12 à 0,74) étaient significativement plus bas dans le groupe gabapentine que dans le groupe témoin placebo, respectivement. Les scores de sédation après administration du médicament (ampleur de l'effet, -3.02; IC -4,28 à-1,77) et de RASS (ampleur de l'effet, 0,41; IC 0,12 à 0,71) étaient significativement plus élevés dans le groupe gabapentine que dans le groupe placebo, respectivement.

Conclusion L'administration de $1200 \mathrm{mg}$ de gabapentine avant la chirurgie réduit les scores d'anxiété préopératoire sur l'ÉÉN ainsi que les scores de catastrophisation de la douleur, et augmente la sédation avant l'entrée en salle d'opération. Ces résultats suggèrent que $1200 \mathrm{mg}$ de gabapentine pourraient constituer une option de traitement pour les patients manifestant des niveaux élevés d'anxiété préopératoire et de catastrophisation de la douleur; toutefois, les propriétés sédatives du médicament et la possibilité d'un delai dans le congé postopératoire dans la population ambulatoire pour chirurgies non urgentes doivent être prises en compte.

Preoperative anxiety is a clinically significant problem for many patients undergoing surgery. Intense preoperative anxiety and fear-based states are associated with a higher 
intensity of acute postoperative pain ${ }^{1}$ and the development of chronic post-surgical pain., ${ }^{2,3}$ Benzodiazepines are firstline treatments for patients who exhibit clinically significant preoperative anxiety. ${ }^{4,5}$ Although novel anti-anxiety techniques/agents continue to be investigated for the pediatric population, ${ }^{6,7}$ there have been very few studies examining novel pharmacological interventions for the treatment of preoperative anxiety in adults.

Recent studies have investigated the efficacy of the $\alpha 2 \delta$ (alpha-2-delta) voltage-dependent calcium channel blockers (gabapentin and pregabalin) for the treatment of preoperative anxiety, and there have been mixed results regarding the efficacy of gabapentin. ${ }^{8-11}$ Patients who received gabapentin $1,200 \mathrm{mg}$ prior to anterior cruciate ligament repair reported less preoperative anxiety on the operating table prior to the induction of anesthesia when compared with patients who received placebo medications. ${ }^{9}$ Results of another study in which gabapentin 1,200 mg was administered preoperatively to psychiatric patients showed that preoperative anxiety in patients treated with gabapentin was statistically significantly lower in the preoperative holding area when compared with patients treated with placebo. ${ }^{11}$ In other studies, gabapentin 1,200 mg did not reduce preoperative anxiety when compared with the benzodiazepine, oxazepam $(15 \mathrm{mg})$, in patients undergoing vaginal hysterectomy, ${ }^{10}$ and gabapentin $600 \mathrm{mg}$ did not provide anxiolysis prior to total hip arthroplasty when administered two hours prior to induction of anesthesia. ${ }^{8}$

Taken together, the results of the four published studies are equivocal. Two studies lacked pre-drug baseline anxiety scores, 9,10 raising the possibility that the two groups differed in preoperative anxiety prior to the intervention. Another study lacked an appropriate placebo-control condition, ${ }^{10}$ which may have masked an effect by the two active medications (gabapentin vs oxazepam) when compared with placebo. The fourth study included patients with low levels of preoperative anxiety, ${ }^{8}$ suggesting a floor effect in which there was little room for gabapentin to reduce anxiety. A summary of previous results is presented in Table 1. Due to differences among the studies in the dose of gabapentin administered as well as methodological problems, the question whether gabapentin has anxiolytic effects when used preoperatively is left unanswered.

In our view, the present randomized placebo-controlled double-blinded trial provides a methodological improvement on previous work performed in this area. First, we measured anxiety prior to drug administration to ensure that any post-drug differences were not due to pre-existing levels of anxiety. Second, we selected a patient population that exhibited moderate to high levels of preoperative anxiety; previous trials have not screened patients for preoperative anxiety. Anxious patients tend to require a longer postoperative hospital stay and can develop cognitive and behavioural sequelae that may have significant negative effects on recovery. ${ }^{12}$ Young anxious female patients have been shown to be at an especially high risk of developing perioperative psychological and physical surgical stress reactions. ${ }^{13,14}$ Beyond anxiety related to the experience of pain in the postoperative period, certain psychological states have also predicted the need for increased postoperative care. Pain catastrophizing is associated with a multitude of pain-related outcomes, including pain severity, decreased pain tolerance, increased post-surgical pain, increased analgesic consumption, and somatization. ${ }^{15-18}$ High levels of pain-related anxiety has also been associated with greater pain severity, disability, and lower quality of life. ${ }^{19}$ Patient factors, such as female sex and younger age, are correlated with heightened fear-based states that lead to increased perioperative pain and anxiety. ${ }^{14,20-22}$

The aim of the present randomized placebo-controlled double-blinded trial was to compare the anxiety-reducing effects of gabapentin with a placebo in moderate to highly anxious female patients about to undergo surgery. Secondary aims included (1) evaluating the magnitude of the linear relationships among the anxiety variables and (2) comparing the two groups in terms of sedation scores, Richmond Agitation-Sedation Scale (RASS) scores, and numerical rating scale (NRS) pain scores. The State-Trait Anxiety Inventories, (STAI)-S and STAI-T, are the "gold standards" for measuring state and trait anxiety, respectively. The STAI-S and STAI-T inventories were included in the present study to achieve a more rigorous assessment of preoperative anxiety than could be achieved simply by using a one-item measure like the NRS. Correlations were computed to ensure that the NRS for anxiety and the STAI-S and STAI-T were, in fact, measuring a similar construct. Between group comparisons were conducted to determine whether gabapentin affected sedation and pain.

\section{Methodology}

The study was reviewed and approved by the Research Ethics Board of the Toronto General Hospital, University Health Network (Toronto, Ontario) on June 19, 2009. Signed informed consent was obtained from each participant at the time of recruitment. The present study was a single-centre randomized placebo-controlled blinded trial.

\section{Study population}

Inclusion criteria included females aged 18-50 yr with American Society of Anesthesiologists physical status I, II, or III and scheduled for non-cardiac surgery with a preoperative anxiety score of greater than or equal to $5 / 10$ on a NRS. Exclusion criteria included the inability to 


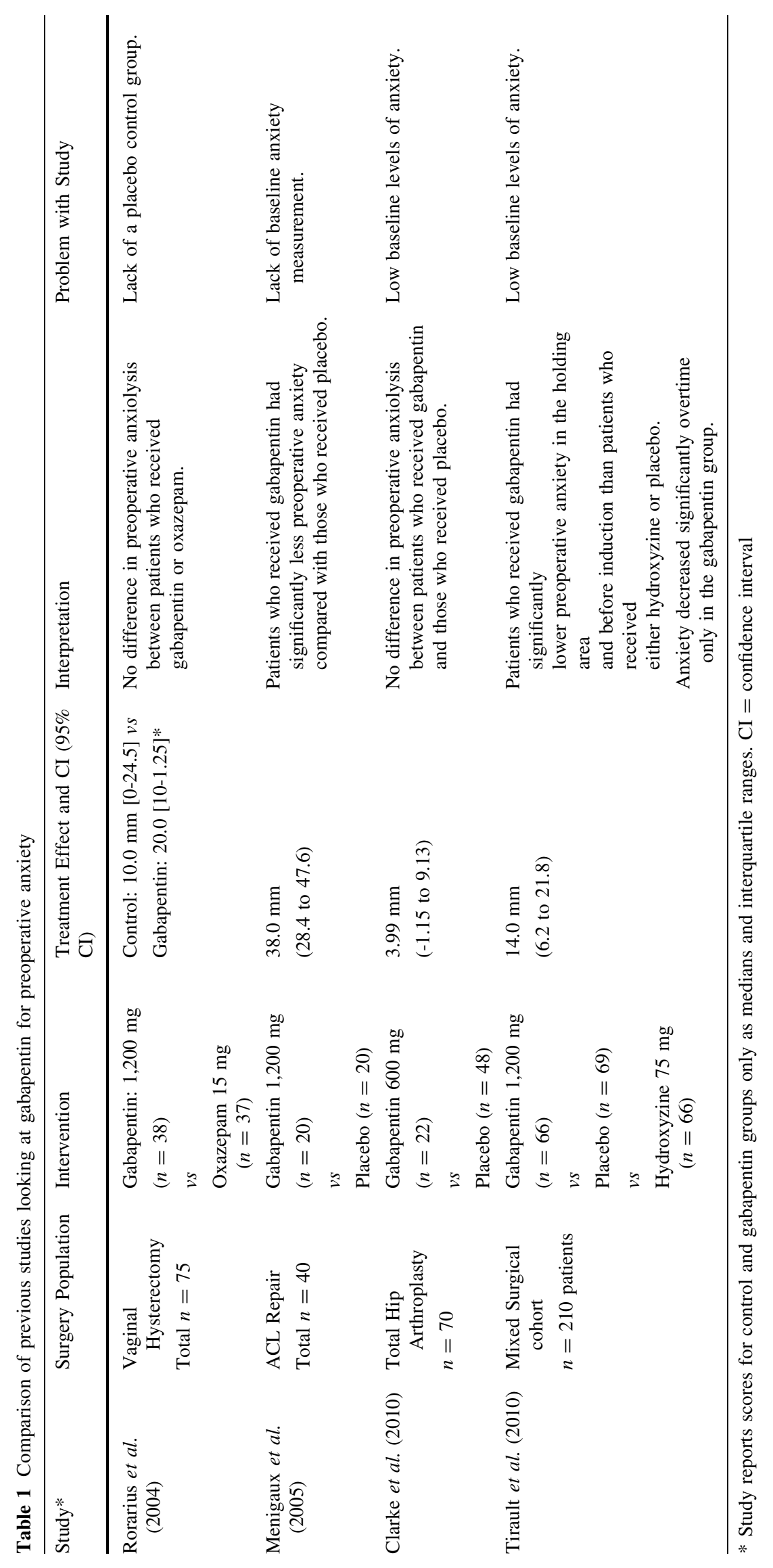


understand English or to provide informed consent; a known allergy to gabapentin; abnormal liver or renal function; known HIV, hepatitis B, or hepatitis C infection; severe mental illness; and diabetic patients on insulin or with impaired renal function (creatinine level $>106 \mu \mathrm{mol} \cdot \mathrm{L}^{-1}$ ). Subjects currently taking gabapentin or pregabalin, those who were pregnant or breastfeeding, or those with a history of drug or alcohol abuse were also excluded.

Drug preparation, dispensing, and randomization

An investigator (J.K.) not otherwise involved with the participants, data collection, or data analysis generated a randomization schedule with StatsDirect statistical software version 2.7.5 (Cheshire, UK) using permuted blocks of varying size (4, 6, and 8) and specifying the group (gabapentin 1,200 mg or placebo) to which participants would be allocated. The randomization schedule was provided to the Toronto General Hospital Investigational Pharmacy that was responsible for the blinding and dispensing of medication. The gabapentin was encased in coloured gelatin capsules identical in all respects to the placebo capsules containing lactose monohydrate. The capsules were dispensed into sequentially numbered identical containers according to the allocation sequence in the randomization schedule. All patients and care providers, including physicians, nurses, and study personnel, were blinded to group allocation.

Potential participants were approached approximately one week before surgery in the preanesthetic clinic to determine their eligibility for participation. The NRS for anxiety was administered to patients to determine eligibility (i.e., a score of greater than 5 out of 10 on the NRS for anxiety); this is not standard practice at our institution. After obtaining informed consent, pre-admission pain questionnaires (i.e., the NRS pain score and the McGill Pain Questionnaire [SF-MPQ-2]) were administered. Consenting participants were then instructed to arrive $2.5 \mathrm{hr}$ prior to their scheduled surgery. Upon arrival at the hospital on the day of surgery, pre-drug administration questionnaires were completed followed by administration of the study drug that had been prepared and dispensed by the Investigational Pharmacy. Participants were then monitored continuously in the preoperative facility by qualified nursing staff. Two hours after ingestion of the study drug, the questionnaires that had been completed prior to taking the drug were re-administered to the participants.

The choice of anesthetic technique, induction, and intraoperative medications were left to the discretion of the attending anesthesiologist who had been informed that the participant was in a research study and had received either gabapentin $1,200 \mathrm{mg}$ or an inert placebo.
Procedure

In addition to the commonly used visual analogue scale (VAS) measurement tool administered for anxiety in the perioperative environment, the Spielberger State-Trait Anxiety Inventories (STAI-S and STAI-T), ${ }^{23}$ the Pain Catastrophizing Scale (PCS), ${ }^{24}$ and the Pain Anxiety Symptoms Scale (PASS $)^{25}$ were administered to assess the efficacy of gabapentin administration for the treatment of preoperative anxiety in young healthy women prior to major surgery. Anxiety level was measured using a 0-10 NRS and the STAI-S and STAI-T. ${ }^{23}$ The pain-anxiety relationship was assessed by the PASS and the PCS. All measures were administered upon arrival at the hospital (pre-treatment) and two hours post-drug administration (post-treatment). Numerical rating scores for pain and sedation were completed one hour after the end of surgery while the patients were in the postanesthetic care unit (PACU). Finally, the study coordinator measured the adverse effects of sedation and agitation by administering the Richmond Agitation-Sedation Scale (RASS) at pre-treatment, post-treatment, and one hour post-surgery in the PACU. ${ }^{26}$ Appendix A outlines in detail the anxiety instruments used in this study; a higher score on these measurement tools represents greater anxiety. The RASS measurement tool is outlined in Appendix B; a lower score (i.e., a negative score) on this measurement tool denotes greater sedation.

\section{Sample size estimate}

Previous work in a sample of 40 patients ( $n=20$ patients per group) found that the mean (standard deviation) preoperative anxiety scores, as measured by a 100-mm VAS, were significantly lower in patients treated with gabapentin than in patients who received placebo [28 (16) $\mathrm{mm}$ vs 66 (15) $\mathrm{mm}$, respectively; $P=0.0001] .{ }^{9}$ Using the above data, we estimated that a sample size of four patients per group would be required to detect a mean difference of $34 \mathrm{~mm}$ by a twotailed Student's $t$ test using a standard deviation of $16 \mathrm{~mm}$, a Type 1 error rate of 0.05 (two-sided), and a power of 0.80 . This sample size seemed unrealistically small largely because of what appeared to us to be a very small standard deviation. We also estimated sample size from data showing that gabapentin reduced preoperative anxiety compared with a placebo control group [20 (21) mm vs 36 (28) mm, respectively] (Tirault et al., 2010), which indicated that 29 patients per group would be needed to detect a $16 \mathrm{~mm}$ difference in anxiety with alpha $=0.05$ (two-sided) and a power of $0.80 .{ }^{11}$ Based on the two studies cited above and given that our primary outcome was a clinically significant decrease in anxiety as measured by the NRS, we recruited 25 patients per group (i.e., using an expected mean difference of $20 \mathrm{~mm}$ and a pooled standard deviation of 21 from the Tirault study). There were no patients lost to follow-up 
because the primary outcome was collected prior to surgery and data collection ended one hour following surgery. A mean difference of $20 \mathrm{~mm}$ would represent, at minimum, a $20 \%$ clinically significant reduction in preoperative anxiety.

\section{Statistical analysis}

Clinical and demographic variables were described with means and standard deviations for continuous data, and frequencies and percentages for categorical data, and they were compared between the groups with Student's $t$ test and Chi square tests, respectively. Summary scores from the different questionnaires were described using medians and interquartile ranges. Post-treatment scores were compared between groups using analysis of covariance with treatment group and baseline scores included as covariates. A biostatistician (N.M.) not otherwise involved in the trial performed data analysis using SAS ${ }^{\circledR}$ statistical software version 9.2 (SAS Institute, Inc., Cary, NC, USA) and R software environment version 2.10 (The R Foundation for Statistical Computing, Vienna, Austria) for the Microsoft Windows XP Professional version 2002, Service Pack 3 (Microsoft Corp., Redmond, WA, USA) operating system. ${ }^{27}$

\section{Results}

Recruitment and retention of patients

Patients were recruited from September 2009 to June 2011. A flow chart outlining the recruitment and retention of study patients is shown in the Figure. Overall, 187 patients were screened for eligibility. Seventy patients did not meet the inclusion criteria (see Figure), and 67 patients declined participation. Forty-four of the 50 women randomly assigned to the two study groups completed the in-hospital protocol. Six patients did not have sufficient time to complete the post-treatment set of study questionnaires and were taken to the operating room expeditiously (see Figure).

\section{Demographic and clinical variables}

The two groups were comparable with respect to age, body mass index, types of surgery, initial pain, anxiety scores at the time of enrolment, duration of surgery, and intraoperative opioid use (Table 2).

Gabapentin anxiolysis intervention

Table 3 shows the median and interquartile ranges as well as point and interval estimates of the study outcome measures for the two groups before and two hours after

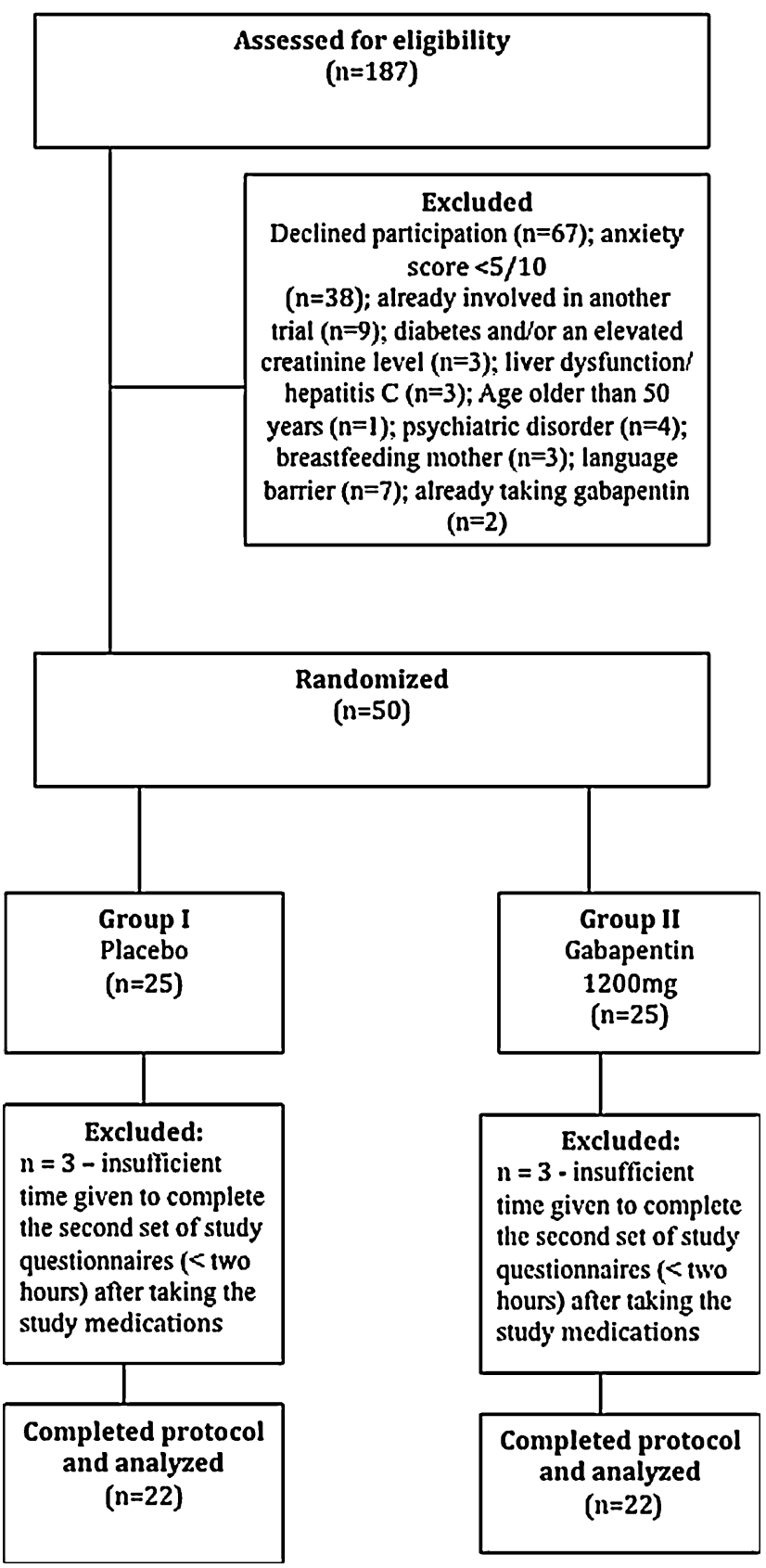

Figure Patient enrolment and study flow. $\mathrm{pt}=$ patient(s)

administration of the study drug preoperatively. Analysis of covariance showed that NRS anxiety scores and PCS scores were clinically lower in the gabapentin group than in the placebo group. Prior to entering the operating room, NRS sedation scores and RASS scores found clinically more sedation in the gabapentin group than in the placebo group; ten patients in the gabapentin group reported a NRS sedation score $\geq 8 / 10$ vs $2 / 10$ in the placebo group $(P<0.05)$. The RASS score showed drowsiness in eight patients receiving gabapentin $v s$ two receiving placebo $(P<0.05)$. 
Table 2 Baseline demographic information and enrolment scores

\begin{tabular}{|c|c|c|}
\hline \multirow[t]{2}{*}{ Variable } & \multicolumn{2}{|l|}{ Group } \\
\hline & $\begin{array}{l}\text { GABAPENTIN } \\
1,200 \mathrm{mg}(n=22)\end{array}$ & $\begin{array}{l}\text { PLACEBO } \\
(n=22)\end{array}$ \\
\hline Age (yr) & $41.6(6.6)$ & $41.8(6.8)$ \\
\hline $\begin{array}{l}\text { Body mass index } \\
\left(\mathrm{kg} \cdot \mathrm{m}^{-2}\right)\end{array}$ & $29.7(11.1)$ & $29.6(9.3)$ \\
\hline $\begin{array}{l}0-10 \text { NRS anxiety score } \\
\text { at enrolment }\end{array}$ & $7.0(1.2)$ & $6.9(1.3)$ \\
\hline $\begin{array}{l}0-10 \text { NRS pain score at } \\
\text { enrolment }\end{array}$ & $0.7(1.8)$ & $1.5(2.4)$ \\
\hline $\begin{array}{l}\text { McGill pain score at } \\
\text { enrolment }\end{array}$ & $1.1(1.1)$ & $1.4(1.4)$ \\
\hline Type of surgery: $n$ & $\begin{array}{l}\text { General: } 6 \\
\text { Gynecological: } 8 \\
\text { Plastics: } 5 \\
\text { Ear nose \& throat: } 3\end{array}$ & $\begin{array}{l}\text { General: } 8 \\
\text { Gynecological: } 8 \\
\text { Plastics: } 3 \\
\text { Ear nose \& } \\
\text { throat: } 3\end{array}$ \\
\hline Duration of surgery (hr) & $5.6(3.2)$ & $4.5(2.7)$ \\
\hline $\begin{array}{l}\text { Intraoperative opioids } \\
\text { administered }\end{array}$ & $\begin{array}{l}\text { Fentanyl }(\mu \mathrm{g}): 247.7 \\
\quad(156.9) \\
\text { Morphine }(\mathrm{mg}): 6.3 \\
\quad(6.3)\end{array}$ & $\begin{array}{l}\text { Fentanyl }(\mu \mathrm{g}): \\
259.1(66.6) \\
\text { Morphine }(\mathrm{mg}): \\
5.6(6.8)\end{array}$ \\
\hline
\end{tabular}

Data are presented as mean (standard deviation) unless otherwise indicated. NRS $=$ numerical rating scale

The largest Spearman correlation coefficient ( $\mathrm{r}$ ) involving the NRS-anxiety, both before and after drug administration, was with the STAI-S inventory [before: $\mathrm{r}(42)=0.64$; $P<0.001$ and after: $\mathrm{r}(42)=0.66 ; P<0.001$, respectively]. In contrast, Spearman correlations between the NRSanxiety and pre-drug total scores on the PASS-20 [r (42) = $0.41 ; P=0.005]$ and PCS $[\mathrm{r}(42)=0.55, P<0.001]$ were considerably larger than the post-drug correlation coefficients [PASS-20, $\mathrm{r}(42)=0.16 ; P=0.30$ and PCS, r $(42)=0.21 ; P=0.17]$. These findings provide initial support for the construct and discriminative validity of the NRS-anxiety as a measure of state anxiety in the pre-surgical setting.

In the PACU after surgery, NRS sedation scores $(P=$ $0.01)$ and RASS scores were clinically higher in patients treated with gabapentin than in patients treated with placebo. No difference in postoperative pain was noted in the PACU (Table 4). Furthermore, 16 patients in the gabapentin group reported a NRS sedation score $\geq 8 / 10 v s$ nine patients in the placebo group $(P<0.05)$. The RASS showed sedation (i.e., a RASS score $\leq-2$ ) in eight patients receiving gabapentin $v s$ three patients receiving placebo.

\section{Discussion}

The aim of the present trial was to compare the anxietyreducing effects of gabapentin $1,200 \mathrm{mg}$ with placebo in moderate to highly anxious patients about to undergo major surgery. Our results indicate that gabapentin $1,200 \mathrm{mg}$ produced clinically significant anxiolysis and lower levels of pain catastrophizing in a female population that exhibited moderate to high anxiety prior to major surgery (Table 2). The present results are consistent with previous studies using gabapentin $1,200 \mathrm{mg}^{9}$ as well as with pregabalin150-300 mg, ${ }^{28-30}$ showing lower anxiety levels compared with placebo. The present results contrast with those of our previous trial using gabapentin $600 \mathrm{mg}$ in which anxiety was not reduced prior to hip arthroplasty. It is possible that doses lower than 1,200 $\mathrm{mg}$ do not reach the therapeutic plasma levels needed to produce clinical anxiolytic effects. ${ }^{31,32}$ Furthermore, the documentation of preoperative anxiety prior to enrolment was not undertaken in previous work. ${ }^{9,10}$

Table 3 Preoperative anxiety, pain, and sedation scores for the two groups before (pre-treatment) and two hours after (post-treatment) administration of placebo or gabapentin prior to surgery

\begin{tabular}{|c|c|c|c|c|c|}
\hline \multirow[t]{2}{*}{ Variable } & \multicolumn{2}{|c|}{ Gabapentin $1,200 \mathrm{mg}(n=22)$} & \multicolumn{3}{|l|}{ Placebo $(n=22)$} \\
\hline & $\begin{array}{l}\text { Pre-treatment } \\
\text { score }\end{array}$ & $\begin{array}{l}\text { Post-treatment } \\
\text { score }\end{array}$ & $\begin{array}{l}\text { Pre-treatment } \\
\text { score }\end{array}$ & $\begin{array}{l}\text { Post-treatment } \\
\text { score }\end{array}$ & $\begin{array}{l}\text { Effect Size \& Confidence } \\
\text { Interval }\end{array}$ \\
\hline Anxiety Score (NRS) & $5.5[2.0-7.0]$ & $2.5[1.0-4.0]$ & $6.0[3.5-8.0]$ & $4.0[2.0-5.0]$ & $1.44(0.19$ to 2.70$)$ \\
\hline McGill Pain Questionnaire & $1.5[0.1-2.0]$ & $0.6[0.1-1.2]$ & $1.0[0.1-1.9]$ & $0.5[0.1-1.2]$ & $0.14(-0.23$ to 0.51$)$ \\
\hline Pain Catastrophizing & $19.5[11.7-29.9]$ & $13.0[6.5-24.7]$ & 20.8 [10.4-29.9] & $15.6[6.5-27.3]$ & $0.43(0.12$ to 0.74$)$ \\
\hline Spielberger - Trait & $37.5[29.0-47.0]$ & $35.5[30.0-44.0]$ & $36.0[30.0-46.0]$ & $34.0[29.0-42.5]$ & $0.01(-0.11$ to 0.13$)$ \\
\hline Spielberger - State & $46.0[40.0-55.0]$ & $40.0[32.0-49.0]$ & $48.0[40.0-58.5]$ & $44.0[33.5-50.5]$ & $0.14(-0.17$ to 0.46$)$ \\
\hline Pain Anxiety Symptoms Scale & $33.5[23.0-50.0]$ & $28.0[13.0-39.0]$ & $39.0[23.0-55.5]$ & $30.5[20.0-48.0]$ & $0.22(-0.12$ to 0.56$)$ \\
\hline Pain Score (NRS) & $0.0[0.0-1.0]$ & $0.0[0.0-1.0]$ & $0.0[0.0-1.5]$ & $0.0[0.0-2.0]$ & $0.51(-0.34$ to 1.35$)$ \\
\hline Sedation Score (NRS) & $2[0.0-6.0]$ & $7[5.0-8.0]$ & $2.0[0.0-5.0]$ & $5[2.0-8.0]$ & $-3.02(-4.28$ to -1.77$)$ \\
\hline Richmond Agitation-Sedation Scale & $0[0-0]$ & $0[-1.0-0.0]$ & $0[0-0]$ & $0[0-0]$ & $0.41(0.12$ to 0.71$)$ \\
\hline
\end{tabular}

Data presented as median [interquartile ranges] and (confidence intervals). NRS = numerical rating scale 
Table 4 Pain and sedation scores for the two groups in the postanesthetic care unit (PACU) one hour after surgery

\begin{tabular}{llll}
\hline & Gabapentin 1,200 mg $(n=22)$ & Placebo $(n=22)$ & $P$ value \\
\hline $\begin{array}{l}\text { Opioids administered with the first hour } \\
\text { of arrival to the PACU }\end{array}$ & Fentanyl $(\mu \mathrm{g}): 8.0(19.0)^{*}$ & Fentanyl $(\mu \mathrm{g}): 25.7(36.3)$ & Morphine $(\mathrm{mg}): 1.3(2.8)$ \\
NRS Pain score & Morphine $(\mathrm{mg}): 0.8(2.1)$ & $5.0[2.0-7.0]$ & 0.05 \\
NRS Sedation score & $4.5[2.0-6.0]$ & $8.0[5.0-9.0]$ & 0.53 \\
Richmond Agitation -Sedation Scale & $8.5[7.0-9.0]^{*}$ & $-1.0[-1.5$ to -0.5$]$ & 0.01 \\
\hline
\end{tabular}

Data presented as median [interquartile range] and mean (standard deviation). ${ }^{*}$ Statistically significant (i.e., $P<0.05$ )

$\mathrm{PACU}=$ postanesthesia care unit; NRS $=$ numerical rating scale

Biopsychosocial models have suggested that psychological outcomes must be considered in addition to physical outcomes in order to understand pain-related outcomes. ${ }^{33}$ Pain catastrophizing is described as the extent to which individuals worry, amplify, and feel helpless about their current or anticipated pain experience. ${ }^{24}$ There is general consensus that catastrophizing involves an exaggerated negative orientation toward noxious stimuli. ${ }^{24}$ Psychological stressors, such as fears surrounding intense pain, are common prior to major surgery. ${ }^{34}$ Thus, the tendency to catastrophize about the impending surgical experience and anticipated pain increases distress and may contribute to a more intense pain experience. ${ }^{18}$ As anxiety increases preoperatively, patient preoperative quality of life suffers inversely. ${ }^{21}$ Recent studies have revealed that pre-surgical pain catastrophizing is a unique predictor of immediate post-surgical pain and the severity of pain up to six weeks after surgery. ${ }^{35}$ Furthermore, increased pain catastrophizing predicted increased pain and poor function one year following total knee arthroplasty. ${ }^{36}$ Our data are the first to suggest that gabapentin may play a role in the reduction of pain catastrophizing and help reduce the negative effect caused by such thinking. Future studies might investigate pharmacological interventions aimed at decreasing pain catastrophizing to determine whether patients realize improvements in post-surgical pain and conceivably postoperative patient function.

It is noteworthy that we found a clinically significant difference between the two groups as measured by the NRSanxiety but not as measured by the gold standard STAI-S scale. Scores on the NRS-anxiety and PCS were statistically significantly lower in the gabapentin group than in the placebo group two hours after drug administration, suggesting that gabapentin may have specific effects on presurgical anxiety and on pre-surgical pain catastrophizing. The absence of an effect for pain anxiety and trait anxiety is consistent with the non-significant post-drug correlations between the NRS-anxiety and these variables. Gabapentin failed to decrease scores on the STAI-S or the PASS. The STAI-S scale evaluates how respondents feel "right now, at this moment". These results suggest that the VAS measurement tool for preoperative anxiety may, in fact, be a more sensitive measurement tool in the perioperative time period than the STAI, ${ }^{23}$ which is considered the gold standard for psychological assessment of high anxiety states in the psychological community. In our study, it is difficult to explain the absence of evidence of post-drug differences between the groups on the STAI-S; however, these results and the relationship with gabapentin administration should be explored in future studies.

Many studies have examined the use of gabapentin for postoperative pain in the perioperative period. Given that pain was a secondary outcome (evaluated by the NRS at the one-hour time point), no conclusions can be drawn due to lack of an early pain reduction. Many studies have reported improved postoperative pain scores well beyond the one-hour time point and reported opioid sparing and pain reductions for hours ${ }^{37}$ and up to several days ${ }^{38}$ after surgery, particulars which this study was not designed to assess. In contrast, only two studies ${ }^{39,40}$ have rigorously documented profiles of adverse effects associated with these medications. In the present study, patients who received gabapentin reported an increase in sedation prior to entering the operating room (Table 3). Anesthesiologists might agree that an increase in sedation prior to the induction of anesthesia is a benefit as long as it is not accompanied by respiratory depression or a clinically significant decrease in the level of patient consciousness. None of the patients who received gabapentin were sedated to a point that compromised their care; every patient was sufficiently alert to complete the questionnaires two hours after study drug administration. Nevertheless, given the effect size of gabapentin on the self-report NRS sedation scores, it is possible that gabapentin may be more sedating than anxiolytic in the preoperative time period, leading to a possible explanation for the lack of an effect on the STAI-S. Clinically, gabapentin $1,200 \mathrm{mg}$ appears to be safe as a preoperative adjunct and has been administered without significant adverse events in many previous trials. The observed RASS scores corresponded with the increase in sedation reported by patients (Table 3) on the second set of questionnaires before they entered the operating room. Table 4 shows that patients treated with gabapentin were clinically more sedated one hour after surgery in the PACU 
compared with patients treated with placebo. Although sedation levels were higher one hour after surgery in patients who received gabapentin, no adverse events were reported, PACU stay was not prolonged, and clinical care was not compromised. It is important to point out that the total dose of intraoperative opioids and the opioids given within the first hour of arrival to the PACU were similar in both groups; therefore, the difference in sedation observed in the PACU is unlikely due to intra and postoperative use of opioids. Given that gabapentin $1,200 \mathrm{mg}$ is a relatively high preoperative dose, consideration should be given to indications of increased postoperative sedation when this medication is used for moderate to severe preoperative anxiety. Gabapentin $1,200 \mathrm{mg}$ administered routinely in the ambulatory setting may delay discharge.

The proposed mechanism of action of gabapentin and pregabalin is believed to be selective inhibitory binding to the alpha-2-delta $(\alpha 2 \delta)$ subunit of voltage-dependent calcium channels in activated neurons; ${ }^{41}$ however, there is emerging evidence that these compounds may interact with other molecular targets within the central nervous system. ${ }^{42}$ Gabapentin was initially developed to mimic the actions of the inhibitory neurotransmitter $\gamma$-aminobutyric acid (GABA). A cyclohexane ring was added to the carbon backbone of GABA to facilitate the transfer of the drug across the blood-brain barrier. ${ }^{43}$ Surprisingly, gabapentin does not bind to or directly modulate $\mathrm{GABA}_{\mathrm{A}}$ receptors, ${ }^{44-46}$ and it does not modulate $\mathrm{GABA}_{\mathrm{B}}$ receptors, except at high concentrations. ${ }^{47}$ On the other hand, in healthy volunteers and studies involving patients with epilepsy, GABA levels were increased after oral ingestion of gabapentin. ${ }^{48,49}$ Furthermore, gabapentin was found to inhibit both the excitatory synaptic transmission in vitro ${ }^{50}$ and the neuronal response to noxious electrical and mechanical stimulation in vivo mediated by $\alpha$-amino-3-hydroxy-5- methyl-4-isoxazolepropionic acid ${ }^{51}$ and decrease glutamate levels in the rat brain. ${ }^{52}$ The above human and rodent data suggest possible mechanisms underlying both the anxiolytic and sedative properties observed in this study.

A limitation to the current study is the fact that we did not control intraoperative anesthesia management and left the care of the patients to the attending anesthesiologist. Second, our sample is comprised solely of women; although unlikely, it is possible that these findings may not be relevant to men. Finally, our primary outcome was collected before arrival at the operating room (a change in anxiety after preoperative administration of gabapentin), and the measures of postoperative pain and sedation were included but limited to the first postoperative hour in the PACU.

In summary, when compared with placebo, gabapentin $1,200 \mathrm{mg}$ administered prior to surgery reduced preoperative anxiety (as measured by a NRS but not the STAI-S) and pain catastrophizing two hours afterward. The patients treated with gabapentin also had an increased level of sedation before entering the operating room, and they were more somnolent one hour after surgery. Gabapentin 1,200 mg may be considered a treatment option for patients who exhibit high levels of preoperative anxiety and pain catastrophizing; however, the sedative properties of the medication and the possibility of delayed postoperative discharge in the elective ambulatory population should be considered. The results presented in this manuscript need to be evaluated in future randomized controlled trials.

Acknowledgements We sincerely thank the staff in the Pain Research Unit at the Toronto General Hospital, particularly Tenille Ranagoonen for her help with patient recruitment and flow. This work was performed in partial fulfillment of Hance Clarke's doctoral dissertation.

Competing interests None declared.

Financial support Hance Clarke is supported by a Canadian Institutes of Health Research PhD Fellowship Award and by a Merit Award from the Department of Anesthesia at the University of Toronto. Joel Katz is supported by a Canada Research Chair in Health Psychology at York University.

\section{Appendix A}

Pain and Anxiety Questionnaires

Numeric Rating Scale (NRS) for Pain Intensity and Anxiety: The NRS consists of a series of numbers ranging from 0 to 10 with endpoints representing the most extreme pain experiences. For pain intensity, $0=$ no pain and $10=$ the worst possible pain, and for anxiety, $0=n o$ anxiety and $10=$ extreme anxiety. Patients choose the number that best corresponds to the intensity of their pain and to extent of their anxiety. The NRS for pain has good reliability and validity and is sensitive to change following pharmacological intervention. ${ }^{53}$

McGill Pain Questionnaire - Short Form-2 (SF-MPQ2): The SF-MPQ- $2^{54}$ is a 22 -item expanded and revised version of the SF-MPQ ${ }^{55}$ designed to measure the qualities of neuropathic and non-neuropathic pain. Exploratory and confirmatory factor analyses revealed the presence of the following four factors or subscales: (1) continuous pain, (2) intermittent pain, (3) neuropathic pain, and (4) affective pain descriptor. Preliminary analyses indicate that the SF-MPQ-2 has very good to excellent psychometric properties.

Pain Catastrophizing Scale (PCS): Pain catastrophizing has been defined as " an exaggerated negative mental set brought to bear during actual or anticipated painful experience". ${ }^{24}$ The $\mathrm{PCS}^{24}$ consists of 13 items describing 
thoughts and feelings that individuals may experience when they are in pain. Each item is rated on a five-point scale ranging from not at all (0) to all the time (4). The PCS yields a total score and three subscale scores assessing (1) rumination, (2) magnification, and (3) helplessness. The PCS has good to excellent psychometric properties. ${ }^{24}$

The State-Trait Anxiety Inventories (STAI): The Spielberger State-Trait Inventories ${ }^{23}$ consist of two self-report scales, one measuring state anxiety and the other measuring trait anxiety. ${ }^{23}$ Each scale consists of 20 statements about how the respondent may feel. Using a four-point Likert scale, they are asked to rate how strongly they agree ("very much so") or disagree ("not at all") with the item on the STAI-S, whereas the responses on the STAI-T are "almost always" or "almost never". The S-Anxiety scale evaluates how respondents feel "right now, at this moment", whereas the T-Anxiety scale evaluates how they feel "generally". This scale has been used extensively in research and clinical practice and has been shown to be valid and reliable. ${ }^{23}$

Pain Anxiety Symptoms Scale-20 (PASS-20): The PASS- $20^{56}$ is a shortened 20 -item version of the original Pain Anxiety Symptoms Scale ${ }^{25}$ designed to measure fear and anxiety responses specific to pain, including avoidance. The PASS-20 has four five-item subscales, including (1) cognitive anxiety, (2) escape and avoidance, (3) fearful thinking, and (4) physiological anxiety. The PASS-20 has been shown to have good to excellent reliability and validity. ${ }^{56}$

\section{APPENDIX B - Richmond Agitation-Sedation Scale}

\begin{tabular}{|c|c|c|}
\hline Score & Term & Description \\
\hline+4 & Combative & $\begin{array}{l}\text { Overtly combative or violent, immediate danger } \\
\text { to staff }\end{array}$ \\
\hline+3 & $\begin{array}{l}\text { Very } \\
\quad \text { agitated }\end{array}$ & $\begin{array}{l}\text { Pulls on or removes tubes }(s) \text { or catheter }(s) \text { or } \\
\text { has aggressive behaviour toward }\end{array}$ \\
\hline+2 & Agitated & staff \\
\hline+1 & Restless & $\begin{array}{l}\text { Frequent nonpurposeful movement or patient- } \\
\quad \text { ventilator dyssynchrony }\end{array}$ \\
\hline 0 & $\begin{array}{l}\text { Alert and } \\
\quad \text { calm }\end{array}$ & Movements not aggressive or vigorous \\
\hline-1 & Drowsy & $\begin{array}{l}\text { Not fully alert, but has sustained (more than } 10 \\
\text { seconds) awakening, with eye contact, to } \\
\text { voice }\end{array}$ \\
\hline-2 & $\begin{array}{l}\text { Light } \\
\quad \text { sedation }\end{array}$ & $\begin{array}{l}\text { Briefly (less than } 10 \text { seconds) awakens with eye } \\
\text { contact to voice }\end{array}$ \\
\hline-3 & $\begin{array}{l}\text { Moderate } \\
\text { sedation }\end{array}$ & Any movement (but no eye contact) to voice \\
\hline-4 & $\begin{array}{l}\text { Deep } \\
\quad \text { sedation }\end{array}$ & $\begin{array}{l}\text { No response to voice, but any movement to } \\
\text { physical stimulation }\end{array}$ \\
\hline-5 & Unarousable & No response to voice or physical stimulation \\
\hline
\end{tabular}

Appendix B continued

Score Term Description

Procedure

1. Observe the patient. Is the patient alert and calm? (score 0)

Does the patient exhibit behaviour that is consistent with restlessness or agitation? (score +1 to +4 using the criteria listed above, under Description)

2. If the patient is not alert, in a loud speaking voice, state the patient's name and direct the patient to open eyes and look at the speaker. Repeat once if necessary. Can prompt the patient to continue looking at speaker.

Patient demonstrates eye opening and eye contact that is sustained for more than 10 seconds (score -1$)$.

Patient demonstrates eye opening and eye contact, but not sustained for 10 seconds (score -2 ).

Patient demonstrates any movement in response to voice, excluding eye contact (score -3 )

3. If the patient does not respond to voice, physically stimulate the patient by shaking shoulder. If there is no response to shaking shoulder, then rub sternum.

Patient demonstrates any movement to physical stimulation (score 4)

Patient demonstrates no response to voice or physical stimulation (score - 5)

\section{References}

1. Katz J, Buis T, Cohen L. Locked out and still knocking: predictors of excessive demands for postoperative intravenous patientcontrolled analgesia. Can J Anesth 2008; 55: 88-99.

2. Forsythe ME, Dunbar MJ, Hennigar AW, Sullivan MJ, Gross M. Prospective relation between catastrophizing and residual pain following knee arthroplasty: two-year follow-up. Pain Res Manag 2008; 13: 335-41.

3. Harden RN, Bruehl S, Stanos $S$, et al. Prospective examination of pain-related and psychological predictors of CRPS-like phenomena following total knee arthroplasty: a preliminary study. Pain 2003; 106: 393-400.

4. Giacalone VF. Antianxiety/sedative drugs. The benzodiazepines. Clin Podiatr Med Surg 1992; 9: 465-79.

5. Wright KD, Stewart SH, Finley GA, Buffett-Jerrott SE. Prevention and intervention strategies to alleviate preoperative anxiety in children: a critical review. Behav Modif 2007; 31: 52-79.

6. Almenrader N, Passariello M, Coccetti B, Haiberger R, Pietropaoli $P$. Premedication in children: a comparison of oral midazolam and oral clonidine. Paediatr Anaesth 2007; 17: 1143-9.

7. Golan G, Tighe P, Dobija N, Perel A, Keidan I. Clowns for the prevention of preoperative anxiety in children: a randomized controlled trial. Paediatr Anaesth 2009; 19: 262-6.

8. Clarke H, Kay J, Orser BA, Gollish J, Mitsakakis N, Katz J. Gabapentin does not reduce preoperative anxiety when given prior to total hip arthroplasty. Pain Med 2010; 11: 966-71.

9. Menigaux C, Adam F, Guignard B, Sessler DI, Chauvin M. Preoperative gabapentin decreases anxiety and improves early functional recovery from knee surgery. Anesth Analg 2005; 100: 1394-9. 
10. Rorarius $M G$, Mennander $S$, Suominen $P$, et al. Gabapentin for the prevention of postoperative pain after vaginal hysterectomy. Pain 2004; 110: 175-81.

11. Tirault M, Foucan L, Debaene B, et al. Gabapentin premedication: assessment of preoperative anxiolysis and postoperative patient satisfaction. Acta Anaesthesiol Belg 2010; 61: 203-9.

12. Rolfson O, Dahlberg LE, Nilsson JA, Malchau H, Garellick G. Variables determining outcome in total hip replacement surgery. J Bone Joint Surg Br 2009; 91: 157-61.

13. Rosen $S$, Svensson M, Nilsson $U$. Calm or not calm: the question of anxiety in the perianesthesia patient. J Perianesth Nurs 2008; 23: 237-46.

14. Sun GC, Hsu MC, Chia YY, Chen PY, Shaw FZ. Effects of age and gender on intravenous midazolam premedication: a randomized double-blind study. Br J Anaesth 2008; 101: 632-9.

15. Edwards RR, Bingham CO 3rd, Bathon J, Haythornthwaite JA. Catastrophizing and pain in arthritis, fibromyalgia, and other rheumatic diseases. Arthritis Rheum 2006; 55: 325-32.

16. Haythornthwaite JA, Clark MR, Pappagallo M, Raja SN. Pain coping strategies play a role in the persistence of pain in postherpetic neuralgia. Pain 2003; 106: 453-60.

17. Roth $M L$, Tripp DA, Harrison MH, Sullivan M, Carson $P$. Demographic and psychosocial predictors of acute perioperative pain for total knee arthroplasty. Pain Res Manag 2007; 12: 185-94.

18. Sullivan MJ, Thorn B, Haythornthwaite JA, et al. Theoretical perspectives on the relation between catastrophizing and pain. Clin J Pain 2001; 17: 52-64.

19. Ocanez $K L$, McHugh RK, Otto MW. A meta-analytic review of the association between anxiety sensitivity and pain. Depress Anxiety 2010; 27: 760-7.

20. Valenzuela Millan J, Barrera Serrano JR, Ornelas Aguirre JM. Anxiety in preoperative anesthetic procedures (Spanish). Cir Cir 2010; 78: 147-51.

21. Anagnostopoulou $M$, Stroumpoulis $K$, Baltayiannis $N$, et al. Quality of life and pre-operative anxiety level in patients scheduled to undergo thoracic surgery. J BUON 2011; 16: 522-7.

22. Perks A, Chakravarti S, Manninen P. Preoperative anxiety in neurosurgical patients. J Neurosurg Anesthesiol 2009; 21: 127-30.

23. Spielberger CD, Gorsuch RL, Lushene R, Vagg PR, Jacobs GA. State-Trait Anxiety Inventory for Adults: Manual. Palo Alto: Mind Garden; 1983.

24. Sullivan MJ, Bishop SR, Pivik J. The Pain Catastrophizing Scale: development and validation. Psychological Assessment 1995; 7: 524-32.

25. McCracken LM, Zayfert C, Gross RT. The Pain Anxiety Symptoms Scale: development and validation of a scale to measure fear of pain. Pain 1992; 50: 67-73.

26. Sessler CN, Gosnell MS, Grap MJ, et al. The Richmond Agitation-Sedation Scale: validity and reliability in adult intensive care unit patients. Am J Respir Crit Care Med 2002; 166: 1338-44.

27. Team RD. R: A language and environment for statistical computing. Vienna, Austria, 2007. Available from URL: http://www. gbif.org/orc/?doc_id=3297 (accessed December 2012).

28. Gonano C, Latzke D, Sabeti-AschrafM, Kettner SC, Chiari A, Gustorff $B$. The anxiolytic effect of pregabalin in outpatients undergoing minor orthopaedic surgery. J Psychopharmacol 2011; 25: 249-53.

29. Spreng UJ, Dahl V, Raeder J. Effect of a single dose of pregabalin on post-operative pain and pre-operative anxiety in patients undergoing discectomy. Acta Anaesthesiol Scand 2011; 55: 571-6.

30. White PF, Tufanogullari B, Taylor J, Klein K. The effect of pregabalin on preoperative anxiety and sedation levels: a doseranging study. Anesth Analg 2009; 108: 1140-5.

31. Beydoun A, Uthman BM, Sackellares JC. Gabapentin: pharmacokinetics, efficacy, and safety. Clin Neuropharmacol 1995; 18 : 469-81.
32. Su TZ, Lunney E, Campbell G, Oxender DL. Transport of gabapentin, a gamma-amino acid drug, by system 1 alpha-amino acid transporters: a comparative study in astrocytes, synaptosomes, and CHO cells. J Neurochem 1995; 64: 2125-31.

33. Keefe FJ, France CR. Pain: Biopsychological mechanisms and management. Current Directions in Psychological Science 1999; 8: 137-41.

34. Pritchard MJ. Managing anxiety in the elective surgical patient. Br J Nurs 2009; 18: 416-9.

35. Sullivan $M$, Tanzer $M$, Stanish $W$, et al. Psychological determinants of problematic outcomes following total knee arthroplasty. Pain 2009; 143: 123-9.

36. Sullivan $M$, Tanzer $M$, Reardon $G$, Amirault D, Dunbar $M$, Stanish $W$. The role of presurgical expectancies in predicting pain and function one year following total knee arthroplasty. Pain 2011; 152: 2287-93.

37. Pandey CK, Sahay S, Gupta D, et al. Preemptive gabapentin decreases postoperative pain after lumbar discoidectomy. Can J Anesth 2004; 51: 986-9.

38. Clarke H, Pereira S, Kennedy D, et al. Gabapentin decreases morphine consumption and improves functional recovery following total knee arthroplasty. Pain Res Manag 2009; 14: 217-22.

39. Clarke H, Pereira $S$, Kennedy $D$, et al. Adding gabapentin to a multimodal regimen does not reduce acute pain, opioid consumption or chronic pain after total hip arthroplasty. Acta Anaesthesiol Scand 2009; 53: 1073-83.

40. Moore A, Costello J, Wieczorek P, Shah V, Taddio A, Carvalho $J C$. Gabapentin improves postcesarean delivery pain management: a randomized, placebo-controlled trial. Anesth Analg 2011; 112: 167-73.

41. Taylor CP. Mechanisms of analgesia by gabapentin and pregabalin-calcium channel alpha2-delta [Cavalpha2-delta] ligands. Pain 2009; 142: 13-6.

42. Bonin RP, Labrakakis $C$, Eng DG, Whissell PD, Koninck $Y D$, Orser BA. Pharmacological enhancement of delta-subunit-containing $\mathrm{GABA}(\mathrm{A})$ receptors that generate a tonic inhibitory conductance in spinal neurons attenuates acute nociception in mice. Pain 2011; 152: 1317-26.

43. Goa KL, Sorkin EM. Gabapentin. A review of its pharmacological properties and clinical potential in epilepsy. Drugs 1993; 46: 409-27.

44. Cheng VY, Bonin RP, Chiu MW, Newell JG, MacDonald JF, Orser BA. Gabapentin increases a tonic inhibitory conductance in hippocampal pyramidal neurons. Anesthesiology 2006; 105: 325-33.

45. Macdonald RL, Greenfield LJ Jr. Mechanisms of action of new antiepileptic drugs. Curr Opin Neurol 1997; 10: 121-8.

46. Rock DM, Kelly KM, Macdonald RL. Gabapentin actions on ligand- and voltage-gated responses in cultured rodent neurons. Epilepsy Res 1993; 16: 89-98.

47. Sills GJ. The mechanisms of action of gabapentin and pregabalin. Curr Opin Pharmacol 2006; 6: 108-13.

48. Kuzniecky R, Ho S, Pan J, et al. Modulation of cerebral GABA by topiramate, lamotrigine, and gabapentin in healthy adults. Neurology 2002; 58: 368-72.

49. Petroff OA, Rothman DL, Behar KL, Lamoureux D, Mattson RH. The effect of gabapentin on brain gamma-aminobutyric acid in patients with epilepsy. Ann Neurol 1996; 39: 95-9.

50. Shimoyama M, Shimoyama N, Hori Y. Gabapentin affects glutamatergic excitatory neurotransmission in the rat dorsal horn. Pain 2000; 85: 405-14.

51. Chizh BA, Scheede M, Schlutz H. Antinociception and (R, S)alpha-amino-3-hydroxy-5-methyl-4-isoxazole propionic acid antagonism by gabapentin in the rat spinal cord in vivo. Naunyn Schmiedebergs Arch Pharmacol 2000; 362: 197-200.

52. Errante LD, Petroff $O A$. Acute effects of gabapentin and pregabalin on rat forebrain cellular GABA, glutamate, and glutamine concentrations. Seizure 2003; 12: 300-6. 
53. Katz J, Melzack R. Measurement of pain. Surg Clin North Am 1999; 79: 231-52.

54. Dworkin RH, Turk DC, Revicki DA, et al. Development and initial validation of an expanded and revised version of the Shortform McGill Pain Questionnaire (SF-MPQ-2). Pain 2009; 144: $35-42$.
55. Melzack R. The short-form McGill Pain Questionnaire. Pain 1987; 30: 191-7.

56. McCracken LM, Dhingra L. A short version of the Pain Anxiety Symptoms Scale (PASS-20): preliminary development and validity. Pain Res Manag 2002; 7: 45-50. 